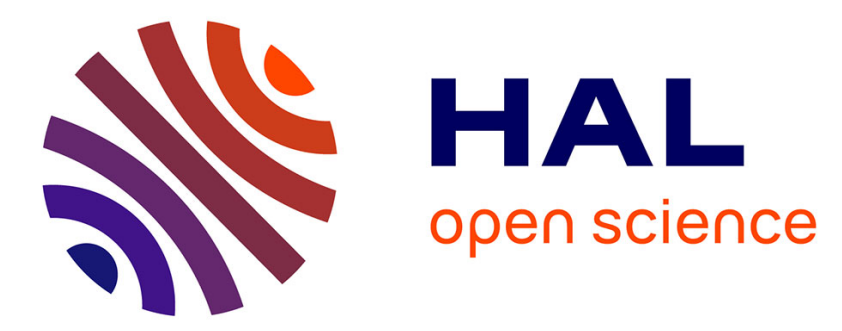

\title{
Control of the Arc Motion in DC Plasma Spray Torch with a Cascaded Anode
}

Rodion Zhukovskii, Christophe Chazelas, Armelle Vardelle, Vincent Rat

\section{To cite this version:}

Rodion Zhukovskii, Christophe Chazelas, Armelle Vardelle, Vincent Rat. Control of the Arc Motion in DC Plasma Spray Torch with a Cascaded Anode. Journal of Thermal Spray Technology, 2020, 29 (1-2), pp.3-12. 10.1007/s11666-019-00969-8 . hal-03091096

\section{HAL Id: hal-03091096 https://hal.science/hal-03091096}

Submitted on 6 Jan 2021

HAL is a multi-disciplinary open access archive for the deposit and dissemination of scientific research documents, whether they are published or not. The documents may come from teaching and research institutions in France or abroad, or from public or private research centers.
L'archive ouverte pluridisciplinaire HAL, est destinée au dépôt et à la diffusion de documents scientifiques de niveau recherche, publiés ou non, émanant des établissements d'enseignement et de recherche français ou étrangers, des laboratoires publics ou privés. 


\title{
Control of the Arc Motion in DC Plasma Spray Torch with a Cascaded Anode
}

\author{
Rodion Zhukovskii, Christophe Chazelas, Armelle Vardelle, Vincent Rat \\ Université de Limoges, IRCER, UMR 7315, 87000 Limoges, France.
}

\begin{abstract}
Two common concerns in DC plasma torches are stability of plasma jet and anode erosion. The challenge is how to get a stable plasma jet with minimal anode erosion. This study tackles this question by using either a swirling gas injection or an external axial magnetic field applied to the Oerlikon SinplexPro ${ }^{\mathrm{TM}}$ plasma torch. A 3-D, time-dependent MHD model of the plasma torch operation was used to predict the value of the external magnetic field and its effect on the heat flux to the anode and plasma jet stability. The special feature of the model is to couple the gas phase and electrodes that makes it possible to follow the anode temperature evolution. For specific operation conditions (anode of $\varnothing 9 \mathrm{~mm}, 500$ A, Ar 60 NLPM) the model predicted that the maximal value of the azimuthal self-magnetic field inducted by the arc current was 0.055 $\mathrm{T}$; it also showed that an external magnetic field of $0.05 \mathrm{~T}$ to $0.1 \mathrm{~T}$ could make it possible to limit the anode erosion without noticeably disturbing the plasma jet issuing from the plasma torch. We expect this approach to help to better understand the arc behavior in commercial plasma torches and control anode erosion.
\end{abstract}

Keywords: plasma spray, plasma torch, electric arc, modeling, magnetic field, electrode erosion, plasma jet stability

\section{Introduction}

Most of the commercial plasma torches used in plasma spraying adopt the same "linear" inside geometry: a rod-shaped doped-tungsten cathode with a conical or round tip and a concentric water-cooled copper anode. The arc strikes from the tip of the cathode to some point on the anode wall where it attaches in the form of a hot column penetrating the cold gas boundary 
layer next to the anode wall $(\operatorname{Ref} 1,2)$. The anode arc attachment is subjected to the electromagnetic forces induced by the self-magnetic field and viscous forces exerted by the cold gas flowing through the anode boundary layer. The combined action of these forces and heat effects at the anode wall causes the arc root to move. In addition, a resonant phenomenon caused by some compressibility effects of the plasma-forming gas in the cathode cavity can make this movement more complex $(\operatorname{Ref} 3,4)$.

The chaotic movement of the arc attachment affects the stability of the plasma jet issued from the plasma torch but helps to maintain the integrity of the anode surface by limiting the residence time of the arc at a specific location. Therefore, one of the key issues for plasma torch designers and users is to find the balance between acceptable anode erosion and plasma jet stability. To limit the axial movement of the arc, the most common way is a sudden expansion of the cylindrical nozzle at the end of the channel (Ref 5) or the use of an insulating insert between the electrodes (Ref $6,7,8,9)$. The first technique results in an arc length generally shorter than the average "self-setting" length (controlled by the arc current, nature and flow rate of the plasma gas and electrode geometry) while the second makes it possible to get an arc length longer than the self-setting length (Ref 6) and produce plasma jets of higher enthalpy. This is the preferred approach for the current commercial plasma spray torches. The anodic arc root motion is then restricted to the anode-ring which ends a stack of copper rings insulated from each other. This configuration makes it possible to increase the gas enthalpy by increasing the arc voltage rather than the arc current and so helps to limit the erosion at the anode arc attachment, the latter depending roughly on the square of the arc current (Ref 9). It is generally combined with a swirling injection of the plasma-forming gas that stabilizes the arc column, drives cold gas toward the nozzle wall and forces a circumferential motion of the arc attachment (Ref 5,10$)$. However, the high viscosity of the arc tends to dampen the vortex injection that is 
generally effective for swirl numbers (ratio of the axial flux of angular momentum to axial flux of the axial momentum normalized by the anode radius) higher than 3 (Ref 11 ).

Another approach is to drive the arc with an externally applied magnetic field. This approach reduces electrode erosion (Ref 12-17) and is used in high-power plasma torches (Ref18) but, to the best of our knowledge, has not been used in commercial plasma spray torches.

A recent paper by Bobzin et al (Ref 19) dealt with the use of permanent magnet of 0.68 or 1.2 T placed on the anode of a single cathode cascaded-anode plasma torch (Oerlikon Metco SinplexPro ${ }^{\mathrm{TM}}$ ). It showed that under the conditions of the study (arc current of 360 and $540 \mathrm{~A}$; gas mixture of 52 SLPM of argon and 8 SLPM of hydrogen), the anode arc root was located in a restricted area (at least during the time of experiments) and the external magnet displaced it to another location.

In this study, we designed a series of numerical simulations also for the SinplexPro ${ }^{\mathrm{TM}}$ plasma torch to investigate the effect of an external magnetic field on the arc attachment at the anode wall. The approach consisted in evaluating i) the magnitude of the self-magnetic field generated by the circulation of the arc current, ii) the magnitude of the external magnetic field that will be necessary to limit the anode erosion while keeping the plasma jet rather stable and iii) the effect of the arc rotation on the anode temperature evolution. First, numerical simulations were performed for different angles of injection of the plasma-forming gas in the arc chamber to compare the effect of the swirling gas injection on the anode arc attachment with that of an external axial magnetic field.

The numerical simulations used a 3D time-dependent model of torch operation implemented in an open source CFD software, Code_Saturne. The model couples the electrodes and electric arc and makes it possible to follow the evolution of electrode temperature and anode arc root location. 


\section{Problem Approach}

\section{Plasma Torch Geometry and Operating Conditions}

Figure 1 shows the actual geometry of the Oerlikon Metco SinplexPro ${ }^{\mathrm{TM}}$ Plasma torch. Its two main features are a rather large cathode $(12.7 \mathrm{~mm}$ in diameter $)$ and a cascaded anode that includes three insulated inserts and the anode part. The latter is lined with tungsten to protect it against arc erosion. The plasma-forming gas is injected around the cathode with an angle of $25^{\circ}$

The torch operating conditions used in this study are listed in Table 1. The numerical simulations were carried out with a 9-mm internal diameter (i.d.) anode and argon as plasmaforming gas although the erosion of anode is low with pure argon. The reason was that the main objective of the simulations was to observe the effect of an external magnetic field on the anodic arc root and not to try to quantify the anode erosion yet.

The operating conditions were drawn from the operating window recommended by the manufacturer. They were selected because previous calculations with this set of conditions were in good agreement with experimental data (Ref 20). For instance, the predicted arc voltage, torch efficiency and specific enthalpy were $74 \pm 2 \mathrm{~V}, 64 \%$ and $13.43 \mathrm{MJ} / \mathrm{kg}$, respectively while the experimental ones were $76 \pm 4 \mathrm{~V}, 63 \%$ and $13.46 \mathrm{MJ} / \mathrm{kg}$, respectively. The specific enthalpy (h) of the plasma jet is defined as the ratio of the total enthalpy of the gas flow to the gas mass flow rate $(\dot{\mathrm{m}})$.

$$
h=\frac{U I \eta}{\dot{m}}
$$

where $\eta$ is the thermal efficiency of the plasma torch.

It represents the energy available per unit mass of the flow and is more informative than the torch power to compare set of operating parameters for a given plasma gas. In addition, as it 
takes into account the loss in the electrode cooling system, a correct prediction of the specific enthalpy requires a correct prediction of both the arc voltage and cooling loss.

\section{Application of the External Magnetic Field}

The idea is i) to force the arc to rotate and spread the heat load to a larger portion of the anode wall and ii) control its rotational velocity via the value of the external magnetic field. The latter can be produced by permanent magnets (Ref 19,21$)$ or a current-carrying solenoid (Ref 5,11 17). The second solution was chosen as the value of the magnetic field strength inside the solenoid can thus be adjusted to the operating conditions with the current flowing around the solenoid and the number of turns per unit length of the solenoid according to the following formula:

$$
B_{\text {ext }}=\frac{N \mu_{0} I_{\text {solenoid }}}{L}
$$

Where $\mathrm{N}$ is the number of turns and $\mathrm{L}$ the length of the solenoid (Ref 22). In the present study $\mathrm{N}$ is equal to 10 and $\mathrm{L}$ to $20 \mathrm{~mm}$. The solenoid radius is $8 \mathrm{~mm}$. The current in the solenoid is adjusted to reach the desired external magnetic field.

In addition, the magnetic field directed along the solenoid axis is uniform in its core and far weaker outside the solenoid. Figure 2 shows the magnetic field for a solenoid that surrounds the gun anode. The resulting Lorentz force is $F_{L}=\left[\vec{J} \wedge \vec{B}_{\text {ext }}\right]$; its direction is illustrated in Fig.3.

\section{Mathematical Model}

The mathematical model was based on the 3D time-dependent conservation equations of momentum, enthalpy and mass coupled with the Maxwell equations of electromagnetic field in the gas phase. It also involved the enthalpy conservation equation and electromagnetic equations in the electrodes. The assumptions introduced for establishing this model were adopted from previous works (Ref 20, 23, 24). They include local thermodynamic equilibrium 
(LTE) in the whole gas phase, weakly compressible and laminar flow (Ref 25). A detailed description of the model and the coupling of the gas phase with electrodes can be found in Reference 20 and only the main characteristics will be reminded in the sections below.

\section{Governing Equations and Boundary Conditions}

The fluid model equations were expressed as a balance of accumulation, net flux by convection and diffusion and net production according to the following equation:

$$
\frac{\partial \psi}{\partial t}+\vec{\nabla} \cdot f_{\psi}=\mathrm{S}_{\psi}
$$

Where $\psi$ is a conserved property, $t$ the time, $f_{\psi}$ the net flux of $\psi$ and $\mathrm{S}_{\psi}$ the net production or depletion rate.

The set of conservation and electromagnetism equations describing the local thermodynamic equilibrium (LTE) plasma is shown in Table 2.

The calculation domain (Fig. 4) used for the computations includes the inside of the plasma torch (electrodes and fluid area) and an outside domain which is as long as the torch inside domain. The mass, energy, momentum and electric potential equation were solved using the boundary conditions listed in Table 3 .

The model was implemented in the free open-source CFD software Code_Saturne (Ref 26) that is based on a co-located Finite Volume approach. Yet, Freton et al (Ref 27) recently showed that for free burning or constricted transferred arc this approach can result in wrong predictions of the self-magnetic field and, thus, velocity fields if a null flux condition is imposed to the components of the magnetic vector potential at the physical limits of the domains. They proposed to calculate exact values of the vector potential at the domain boundaries by using the Biot and Savart (B\&S) law. 
Therefore, in the simulations the magnetic vector potential $\vec{A}$ was calculated at the domain boundaries with the Biot \& Savart formulation after equation (3) (Ref 20, 27)

$$
\vec{A}(\vec{r})=\frac{\mu_{0}}{4 \pi} \iiint_{\text {domain }} \frac{\vec{J}\left(\overrightarrow{r^{\prime}}\right)}{\left|\vec{r}-\overrightarrow{r^{\prime}}\right|} d V
$$

where $r$ denotes as the distance from the origin of coordinates to the boundary face for which the boundary value is computed, $r^{\prime}$ denotes as the distance from the origin of coordinates to the cell with the current source taken into account in the integral calculation and $\left(\vec{r}-\overrightarrow{r^{\prime \prime}}\right)$ is the vector from the current source to the boundary face for which the boundary value is computed. The electric current density in the plasma flow was calculated by using a "voltage control" approach. It consists in imposing first an arbitrary voltage drop between the electrodes at the beginning of calculations: the anode voltage was set at $0 \mathrm{~V}$ and cathode voltage at $-\Phi(t)$ where $\Phi(t)$ was the voltage drop between the electrodes. The latter was then recalculated at each time step to reach the prescribed electric current intensity. For that, the integral of the Joule effect was estimated in the whole simulation domain and compared to the product of the prescribed current intensity (I) and voltage $(\Phi)$ applied to the electrodes. If the resulting total Joule power is higher or lower than this product, the value of $\Phi(t)$ is decreased or increased, respectively, by using an adjustment factor $\mathrm{K}_{\text {adjustment }}$.

The latter was calculated by the following formula:

$$
K_{\text {adjustment }}=\frac{I_{\text {imposed }}}{I_{\text {computed }}}=\frac{I_{\text {imposed }} \cdot V_{\text {prev }}}{\int_{\text {domain }} Q_{J}(\vec{r}) d V}
$$

where $\mathrm{I}_{\text {imposed }}$ is the prescribed current intensity, $\mathrm{V}_{\text {prev }}$ the voltage predicted at the previous time step, and $\mathrm{Q}_{J}$ the Joule heating $\left(\mathrm{Q}_{J}=\vec{E} \cdot \vec{J}\right)$ where $\vec{E}$ and $\vec{J}$ are the electric field and current density, respectively.

One iteration was sufficient for each time step.

The new voltage after correction is expressed as follows: 
$V_{\text {new }}=V_{\text {prev }} \cdot K_{\text {adjustment }}$

As a result, the voltage is a predicted value and not an imposed one. This voltage scaling mechanism is described in details in (Ref 28, 29) and was also used in (Ref 16, 30)

\section{Computational details}

The calculations were performed with a mesh of $1 \mathrm{M}$ cells: $800 \mathrm{k}$ in the gas phase, $150 \mathrm{k}$ in the cathode and $50 \mathrm{k}$ in the anode. This choice resulted from a preliminary investigation of the effect of grid density on the results. This investigation showed that the effect of cell size was significant when the cell number increased from $400 \mathrm{k}$ to $1 \mathrm{M}$, but small when it increased from $1 \mathrm{M}$ to $2 \mathrm{M}$. As the $2 \mathrm{M}$ cell mesh require significant computational resources and time and the key indicators were the same with $1 \mathrm{M}$ or $2 \mathrm{M}$ cell grids, the $1 \mathrm{M}$ cell grid was chosen as the best compromise between rate of convergence, solution accuracy and CPU time required.

The calculations were carried out on a 12-core Processor Intel® Xeon® E5-2670 v3. With the $1 \mathrm{M}$ cell grid, they took about $17 \mathrm{~h}$ for 10000 -time steps that represent $1 \mathrm{~ms}$ of the actual torch operation time.

\section{Results and Discussion}

It should be noted that in the past the model has been validated against experimental values (arc voltage and torch thermal efficiency) and post-mortem observation of the electrodes for the present configuration of the torch (swirling injection of the plasma-forming gas with a $25^{\circ}$ angle and no external magnetic field; Ref 20). However, the numerical predictions of this study could not be experimentally validated as neither the injection angle, of $45^{\circ}$, nor the external magnetic field are implemented in SinplexPro as yet. The objective of this work was to investigate the effect of different angles of gas injection and magnitude of external magnetic field on the electrode wall temperature and jet stability, to inform possible further torch development. 


\section{Effect of the Vortex Injection Gas on Anode Arc Attachment}

With the set of plasma operating conditions given in Table 1, the gas injection angle was varied between 0 and $45^{\circ}$. The gas injection without vortex (injection angle $=0^{\circ}$ ) was used to check that the model does not predict any angular displacement of the anode arc attachment when the gas is injected parallel to the plasma torch axis.

The degree of swirling of the flow can be characterized by the Swirl Number $S_{\mathrm{w}}$ that compares the axial flux of the tangential momentum to the axial flux of the axial momentum normalized by the anode radius $\left(R_{0}\right)(\operatorname{Ref} 11)$,

$$
S_{W}=\frac{\int_{S} \rho u w r d S}{R_{0} \int_{S} \rho u^{2} d S}
$$

Where $u$ and $w$ are the gas velocity components in the axial and azimuthal directions, respectively and $\mathrm{S}$ the nozzle cross section.

Table 4 shows the variation of the swirl number from the gas injection inlet to the torch nozzle exit for gas injection angles of $0,10,25$ and $45^{\circ}$ respectively. As expected, its value was zero in the whole torch when the gas was injected in parallel to the torch axis. The gas swirl generated at the plasma-forming gas inlet for a gas injection angle varying between 10 and $45^{\circ}$ progressively decayed along the length of the torch essentially because of the high viscosity of the hot arc column. In the actual plasma torch, the gas is injected with an angle of $25^{\circ}$ as shown in Fig. 5. If the swirling number reaches 1.2 at the gas inlet, it decreases to 0.015 at the nozzle exit and so has little effect on the anode arc attachment. The velocity streamlines are nearly parallel to the torch axis. A gas injection angle of at least $45^{\circ}$ (Fig. 6) is necessary to cause a significant displacement of the arc. If the circumferential velocity of the anode arc attachment (i.e.; the velocity of the rotational motion of arc attachment) is very low for a gas injection angle of $25^{\circ}$, it reaches $30 \mathrm{~m} / \mathrm{s}$ for an angle of $45^{\circ}$ as shown in Fig. 7. This increase comes along with 
a significant decrease in the maximum anode wall temperature (Fig 8), defined as the temperature of the hottest cell in the anode wall. It should be noted that, in this study that used only argon as plasma-forming gas, the predicted maximum temperature of the anode tungsten liner was below the tungsten melting point (3693K) when a swirling injection was used. The situation would be different if hydrogen was added to the plasma gas because of a more constricted anode arc attachment and higher thermal conductivity of the gas ( $\operatorname{Ref} 31,32$ ).

Under the operating conditions given in Table 1 (high arc current and rather low gas flow rate), the experimentally observed behavior of the arc attachment is a back and forth movement on a line, which favors the erosion of the anode and causes an asymmetry of the jet at the outlet of the nozzle. The predicted temperature of the cathode and anode tungsten liner for straight gas injection is shown in Fig. 9. The averaged plasma enthalpy and mass flow rate for straight gas injection are illustrated in Fig. 10.

\section{Effect of the Axial External Magnetic Field on Anode Arc Attachment}

The distribution of the self-induced magnetic field in the axial plane of the torch nozzle is presented in Fig. 11. It clearly shows the shape and length of the electric arc and particularly the location of its center characterized by a zero value of the magnetic field. The self-induced magnetic field is azimuthal, as expected. Values up to $0.055 \mathrm{~T}$ are encountered in the anodic and cathodic jets close to the electrodes.

The use of a solenoid around the torch body makes it possible i) to vary the intensity of the current flowing in this solenoid to obtain magnetic field values close to that of the self-induced field and ii) numerically observe the effect of the external magnetic field on the arc attachment movement on the anode surface.

Fig. 12 displays the time-dependent electric current streamlines and electrode temperature when an external magnetic field of $0.05 \mathrm{~T}$ is applied. This magnetic field can be produced by a current 
of $90 \mathrm{~A}$ in the solenoid described above. It forces the arc attachment to move on the anode wall with a speed around $24 \mathrm{~m} / \mathrm{s}$. The corresponding arc rotation frequency in this case is around $800 \mathrm{~Hz}$. To obtain the external magnetic field of $0.1 \mathrm{~T}$ the electric current should be doubled up to $180 \mathrm{~A}$. The local heating of the anode where the arc attaches is also visible in the pictures. As expected, the rotation of the anode arc root spreads the heat load on the anode wall during the arc rotation. Contrary to the gas swirling injection, which is effective on the arc attachment for gas injection angle at least equal to $45^{\circ}$, the application of an external magnetic field causes the rotation of the arc attachment for the whole magnetic field range selected in this study.

Figures 13 and 14 show the distribution of the velocity streamlines for two values of the external magnetic field: $0.05 \mathrm{~T}$ and $0.2 \mathrm{~T}$, respectively. For the $0.05 \mathrm{~T}$ magnetic field, the flow issuing from the nozzle is little disturbed by the lateral displacement of the arc root on the anode wall while the $0.2 \mathrm{~T}$ magnetic field produces more unstable velocity streamlines lines, with a more important rotational component, and an arc column that is already destabilized upstream from the anode ring.

As shown in Fig. 15, the predicted rotation velocity of the arc increases, as expected, with the external magnetic field, which allows controlling the maximum temperature of the anode surface. Its variation with the strength of the magnetic field is presented in Fig. 16. The swirl numbers of the flow generated by the magnetic field at the middle of the torch and at the nozzle exit are given in Table 5. It shows that the anode erosion of the SinplexPro plasma torch could be controlled by applying an axial external magnetic field. When the torch operates with argon (60 NLPM) as plasma gas and an arc current of $500 \mathrm{~A}$, a magnetic field of $0.05 \mathrm{~T}-0.1 \mathrm{~T}$ seems adequate to limit the erosion of the anode without noticeably disturbing the plasma jet produced at the outlet of the nozzle. However, contrarily to the swirling injection, it does not provide any convective cooling of the anode. 
The application of the external magnetic field results also in more homogeneous plasma jet properties at the nozzle exit close to the point where the solid or liquid feedstock could be injected (Fig. 17).

\section{Conclusions}

This study attempted to determine the strength of the external magnetic field that could be applied to reduce the erosion of the anode of a SinplexPro plasma torch. Actual geometry and operating conditions of the torch were considered and argon was used as plasma forming gas. The numerical simulations made it possible to determine i) the maximum value of the selfinduced magnetic field value, ii) the values of the external magnetic field that could be applied to the anode and iii) investigate their combined effect on anode arc attachment and plasma jet stability. For a $9 \mathrm{~mm}$ diameter anode, 60 NLPM of argon and $500 \mathrm{~A}$ of arc current the maximum self-magnetic field was found to be $0.055 \mathrm{~T}$ close to the electrodes and the external magnetic field was varied between $0.025 \mathrm{~T}$ and $0.2 \mathrm{~T}$. The numerical simulations also predicted that a gas swirling injection of $45^{\circ}$ could be another solution to limit the anode erosion without using an additional magnetic field.

However, if the predicted trends for a specific parameter variation are reliable, the values of the predictions should be cautiously taken as they may depend on the assumptions of the model.

In this work a LTE model was used with the arc reattachment model proposed by Nemchinsky (Ref 33) to ensure the flow of electrical current from the plasma column to the anode. In short, this model assumes that the electron temperature in the cold boundary layer next to the anode wall does not decrease as much as the heavy particle temperature and that some residual electrical conductivity subsists in this layer. However, questions may rise about the effect of these assumptions on the arc root shape and its motion when it subjected to an external axial magnetic field (Ref 34). Therefore, to get rid of this questioning, the work in progress deals with the implementation of a NLTE model (Ref 35-38). Also, the use of plasma-forming gas 
mixtures of argon and hydrogen is under consideration but this requires to have the nonequilibrium thermodynamic and transport properties of the gas mixtures.

\section{Acknowledgments}

The authors would like to thank Alexander Barth and Hartmut Koschnitzke, Oerlikon Metco Wohlen, Switzerland, Bernd Distler and Jose Colmenares, Oerlikon Metco, Westbury, USA for valuable discussion, Yvan Fournier, EDF R\&D, Chatou, France for help with Code_Saturne and Frederic Bernaudeau and Nicolas Calvé, IRCER, for their technical help with the computers.

\section{References}

1. Z. Duan and J. Heberlein, Arc Instabilities in a Plasma Spray Torch, J. Therm. Spray Technol., 2002, 11, p 44-57

2. E. Moreau, C. Chazelas, G. Mariaux, A. Vardelle, Modeling the Restrike Mode Operation of a DC Plasma Spray Torch, J. Therm. Spray Technol., 2006, 15, p 524-530

3. J.F. Coudert, V. Rat, D. Rigot, Influence of Helmholtz Oscillations on Arc Voltage Fluctuations in a dc Plasma Spraying Torch, J. Phys. D: Appl. Phys., 2007, 40, p 7357-7366

4. V. Rat, J.F. Coudert, Improvement of Plasma Spray Torch Stability by Controlling Pressure and Voltage Dynamic Coupling, J. Therm. Spray Technol., 2011, 20, p 20-28

5. M.F. Zhukov, I.M. Zasypkin, Thermal Plasma Torches, Cambridge Int Science Publishing (Cambridge, 2007)

6. M.F. Zhukov, Electric arc Plasma Torches, Thermophysics Institute, Siberian Division of the Academy of Sciences (Novosibirsk, USSR, 1980), in Russian 
7. R. Chidambaram Seshadri, R. \& S. Sampath, Characteristics of Conventional and Cascaded Arc Plasma Spray-Deposited Ceramic Under Standard and High-Throughput Conditions, J. Therm. Spray Technol., 2019, 28, p 690-705

8. Bobzin, K. \& M. Öte, Modeling Multi-Arc Spraying Systems, J. Therm. Spray Technol., 2016, 25, p 920-932

9. K.D. Landes, M. Dzulko, E. Theophile, and J. Zierhut, New Developments in DC Plasma Torches, High Temp. Mater. Processes, 2002, 6(3), p 10

10. P. Chyou and E. Pfender, Modeling of Plasma Jets with Superimposed Vortex Flow, Plasma Chem. Plasma Process., 1989, 9(2), p 291-32811

11. C.L. Felipini and M.M. Pimenta, Some Numerical Simulation Results of Swirling Flow in D.C. plasma torch, J. Phys.: Conf. Ser., 2015, 591, 012038

12. R. Westhoff and J. Szekely, A Model o Fluid, Heat Flow, and Electromagnetic Phenomena in a Nontransferred Arc Plasma Torch, J. Appl. Phys., 1991, 70(7), p 3455-3466 13. R.N. Szente, R.J. Munz, and M.G. Drouet, Arc Velocity and Cathode Erosion Rate in a Magnetically Driven Arc Burning in Nitrogen, J. Phys. D: Appl. Phys., 1988, 21(6), p 909913

14. P. Kotalik and H. Nishiyama, An Effect of Magnetic Field on Arc Plasma Flow, IEEE Trans. Plasma Sci., 2002, 30(1), p 160-161

15. J.M. Park, K.S. Kim, T.H. Hwang, and S.H. Hong, Three-dimensional Modeling of Arc Root Rotation by External Magnetic Field in Non-Transferred Thermal Plasma Torches, IEEE Trans. Plasma Sci., 2004, 32(2), p 479-487 
16. M. Baeva and D. Uhrlandt, Non-equilibrium Simulation of the Spatial and Temporal Behavior of a Magnetically Rotating Arc in Argon, Plasma Sources Sci. Technol., 2011, 20(3), 035008

17. V. Nemchinsky, A Method to Reduce Electrode Erosion in a Magnetically Driven Rotating Arc, IEEE Trans. Plasma Sci., 2016, 44(12), p 3474-3478

18. A.S. Prince, R.C. Bunker, and T. Lawrence, Plasma Torch Testing for Thermostructural Evaluation of Rocket Motor Nozzle Materials, 25th Joint Propulsion Conference, Monterey, CA, July 10-13, 1989, 6 p

19. K Bobzin, M Öte, M A Knoch, H Heinemann1, S Zimmermann and J Schein, Influence of External Magnetic Fields on the Coatings of a Cascaded Plasma Generator, IOP Conf. Ser.: Mater. Sci. Eng., 2019, 480012004

20. R. Zhukovski, C. Chazelas, A.Vardelle, V.Rat, B.Distler, Effect of Boundary Conditions on Reliability of DC Plasma Models, submitted to J. Therm. Spray Technol.

21. Guggenheim L, Schwenk A, Zimmermann S, Schein J and Landes K Untersuchungen zum Einfluss von Permanentmagneten auf das physikalische Verhalten von kaskadierten, wandstabilisierten Lichtbögen und keramisch gespritzten Schichten, GTV Kolloquium Thermisches Spritzen \& Laser Cladding (Luckenbach, 7.09.2018) ed K Nassenstein and K von Niessen, 2018, p 95-101

22. David Halliday, Fundamentals of Physics, Volume 1, Wiley, 2005)

23. M. Alaya, C. Chazelas, A.Vardelle, Parametric Study of Plasma Torch Operation Using a MHD Model Coupling the Arc and Electrodes, J. Therm. Spray Technol., 2015, 24(1-2), p $3-10$

24. J.P. Trelles, C. Chazelas, A. Vardelle, J.V.R. Heberlein, Arc Plasma Torch Modeling, J. Therm. Spray Technol., 2009, 18(5-6), p 728 
25. M. Shigeta, Turbulence Modelling of Thermal Plasma Flow, J. Phys. D: Appl. Phys., 2016, 49, 493001

26. Code_Saturne https://www.code-saturne.org/cms/ Accessed 12 June 2019

27. P. Freton, J.J. Gonzalez, M. Masquere, and F. Reichert, Magnetic Field Approaches in DC Thermal Plasma Modelling, J. Phys. D: Appl. Phys., 2011, 44, p 345-202

28. Code Saturne 5.0.0 Theory Guide, EDF R\&D, 2017, p 393-398, in French https://www.code-saturne.org/cms/sites/default/files/docs/5.0/theory.pdf Accessed 12 June 2019

29. A. Gleizes, J. J. Gonzalez, P. Freton, Thermal plasma modelling J. Phys. D: Appl. Phys., 2005, 38, R153

30. Y. Abdo, V. Rohani, F. Cauneau, and L. Fulcheri, New perspectives on the dynamics of AC and DC plasma arcs exposed to cross-fields. J. Phys. D Appl. Phys., 2017, 50(6), 065203

31. P. Fauchais, J.V.R. Heberlein, M. Boulos, Thermal Spray Fundamentals: From Powder to Part. Springer, NewYork, 2014, p 402

32. M.F. Zhukov, I.M. Zasypkin, Thermal Plasma Torches, Cambridge Int Science Publishing, Cambridge, 2007

33. V. Nemchinsky, Arc Discharge Anode Reattachment: Simple Model, IEEE Trans. Plasma Sci., 2014, 42, p 12

34. C. Chazelas, J.P. Trelles, A. Vardelle, The Main Issues to Address in Modeling Plasma Spray Torch Operation, J. Therm. Spray Technol., 2017, 26(1-2), p 3-11

35. J.P. Trelles, J.V.R. Heberlein, and E. Pfender, Non-equilibrium Modelling of Arc Plasma Torches, J. Phys. D: Appl. Phys., 2007, 40(19) p 5937-5952 
36. P. Freton, J.J. Gonzalez, Z. Ranarijaona, J. Mougenot, Energy Equation Formulations for Two Temperature Modelling of 'Thermal' Plasmas, J. Phys. D Appl. Phys., 2012, 45, 465206

37. J. P. Trelles, J., S. Modirkhazeni, Variational multiscale method for nonequilibrium plasma flows, Comput. Methods Appl. Mech. Engrg., 2014, 282, p 87-131

38. P. Liang, and R. Groll, Numerical Study of Plasma-Electrode Interaction During Arc Discharge in a DC Plasma Torch, IEEE Trans. Plasma Sci., 2018, 46(2), p 363-372 


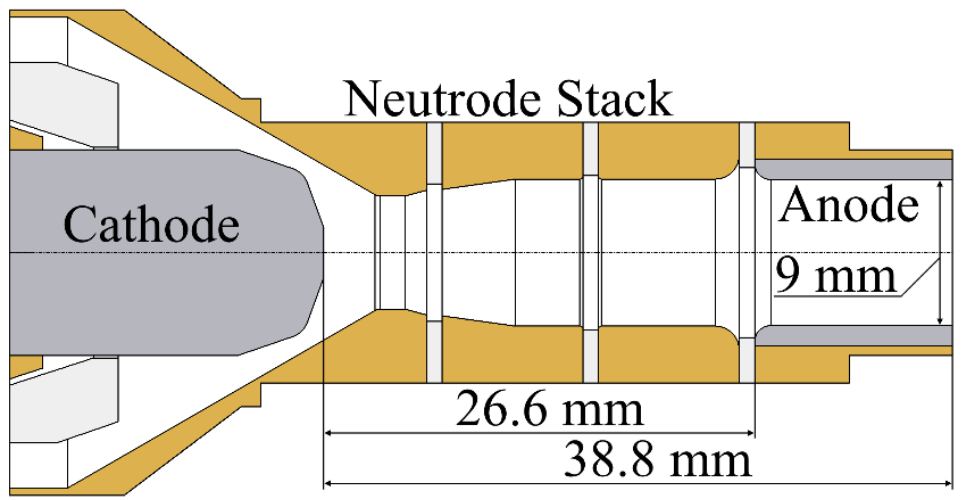

Fig. 1 SinplexPro ${ }^{\mathrm{TM}}$ plasma torch scheme

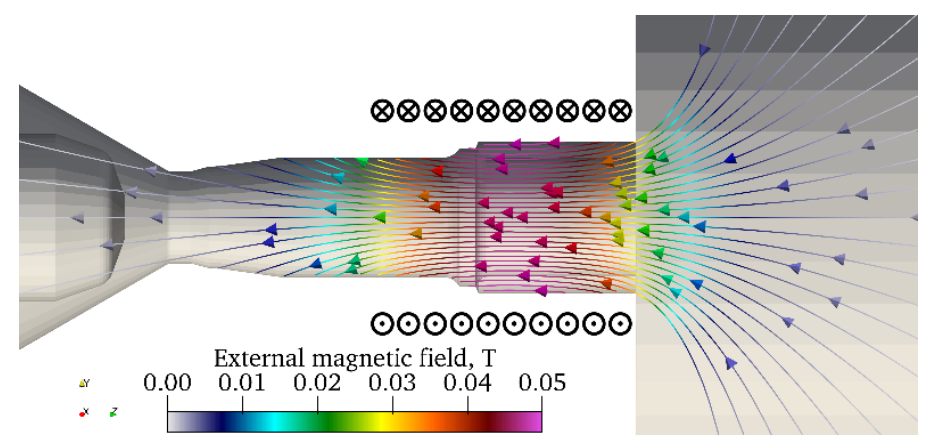

Fig. 2 Magnetic field produced by a solenoid around the torch

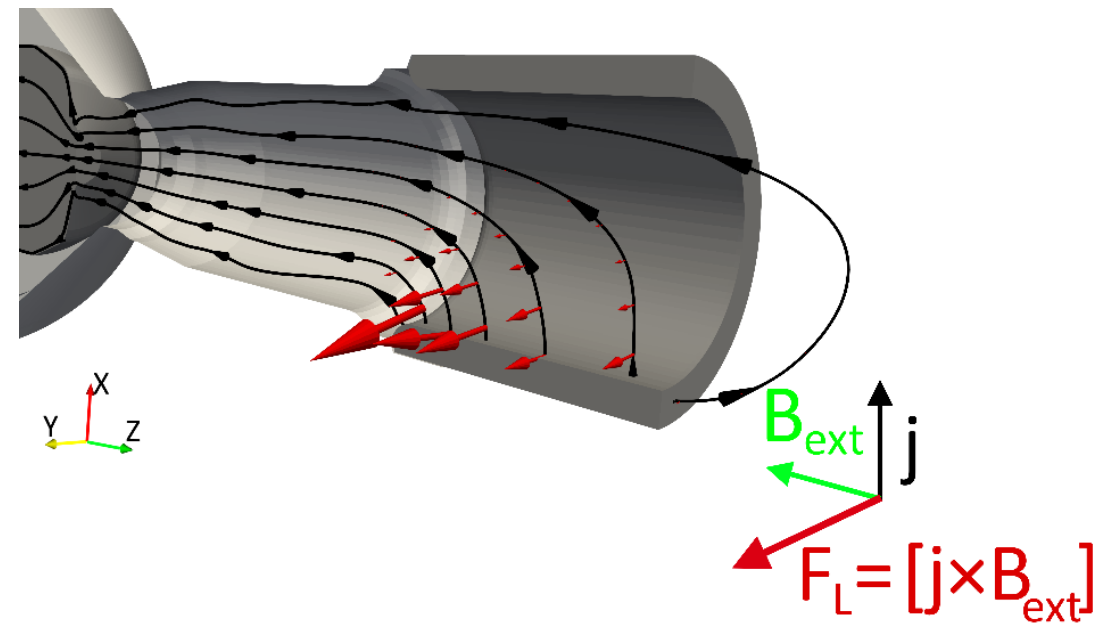

Fig.3. Electric current lines in black and the Lorentz force in red exerted on the moving charge carriers by the external magnetic field in the torch 


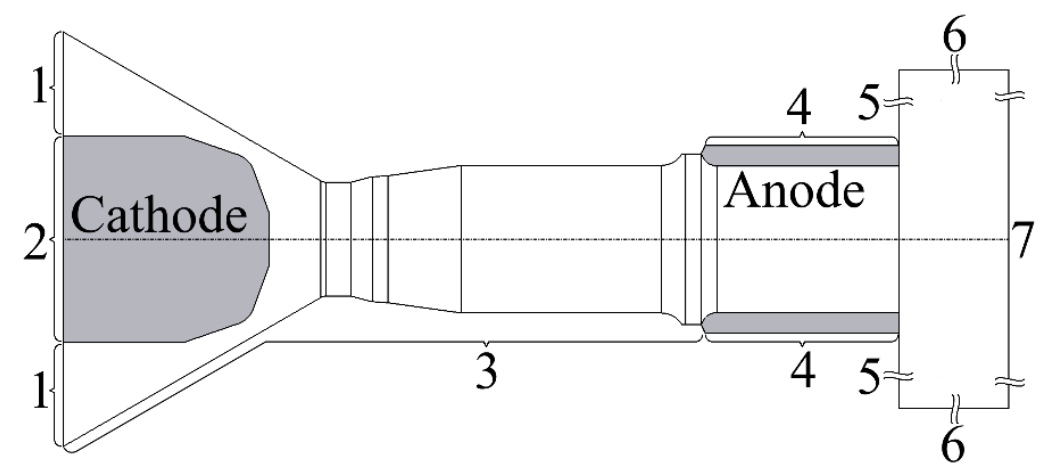

Fig. 4 Boundaries of the computational domain: 1: inlet of plasma-forming gas; 2: rear of the cathode; 3: electrically insulating inter-electrode; 4: rear of the anode; 5 and 6: free boundaries; 7: outlet

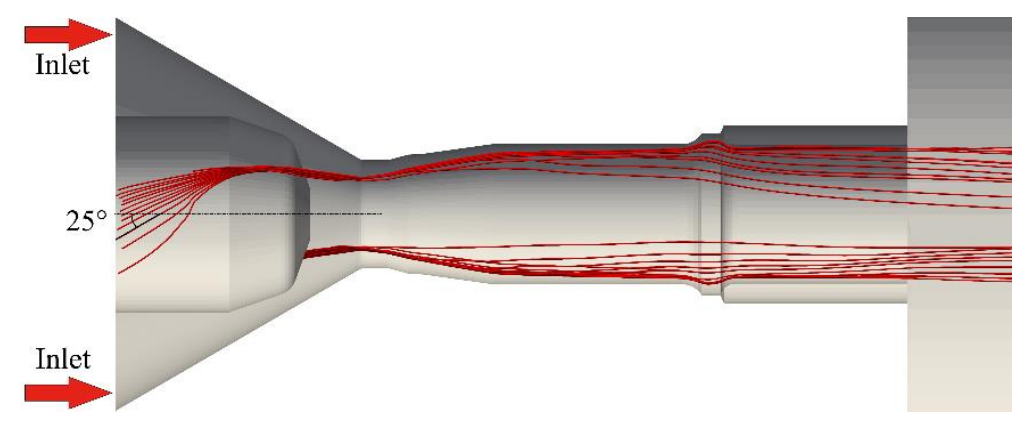

Fig. 5 Gas velocity streamlines with a plasma-forming gas injection angle of $25^{\circ}$ and no external magnetic field

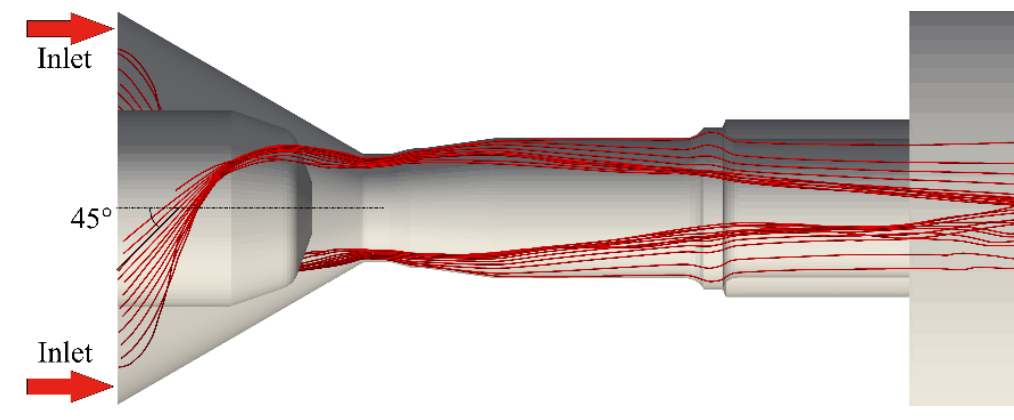

Fig. 6 Gas velocity streamlines with a plasma-forming gas injection angle of $45^{\circ}$ and no external magnetic field 


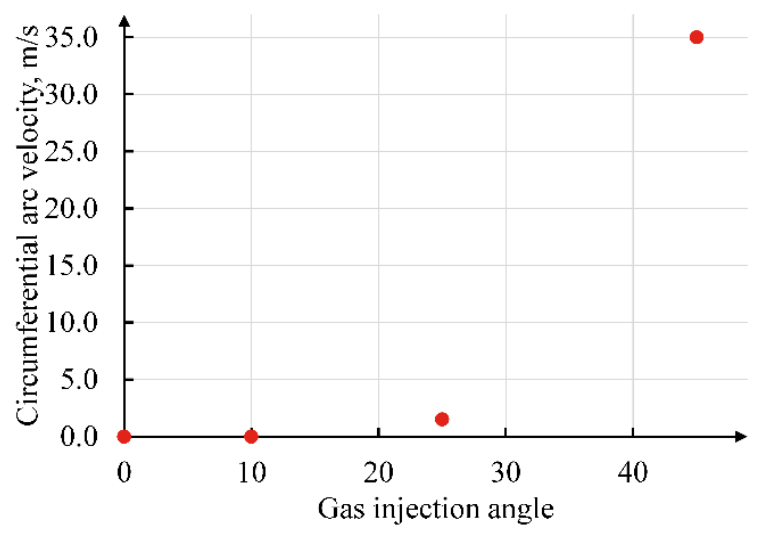

Fig. 7 Variation of the anode arc attachment velocity with the plasma-forming gas injection angle (no external magnetic field)

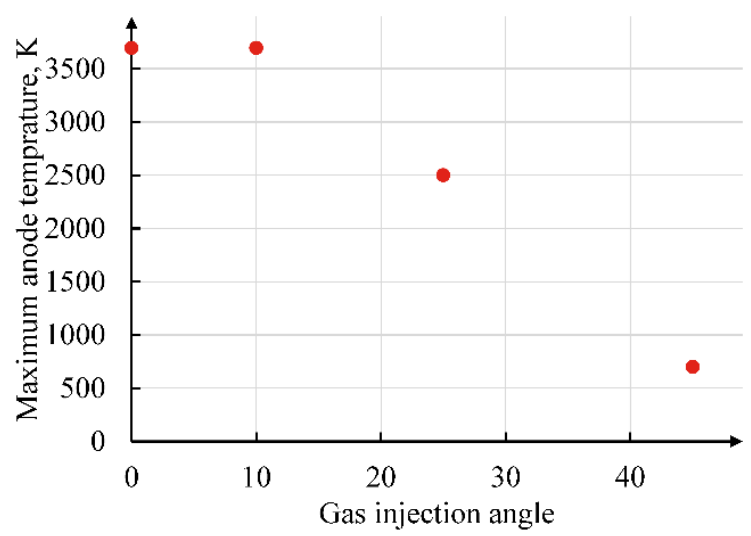

Fig. 8 Variation of the maximum anode temperature with the plasma-forming gas injection angle (no external magnetic field)

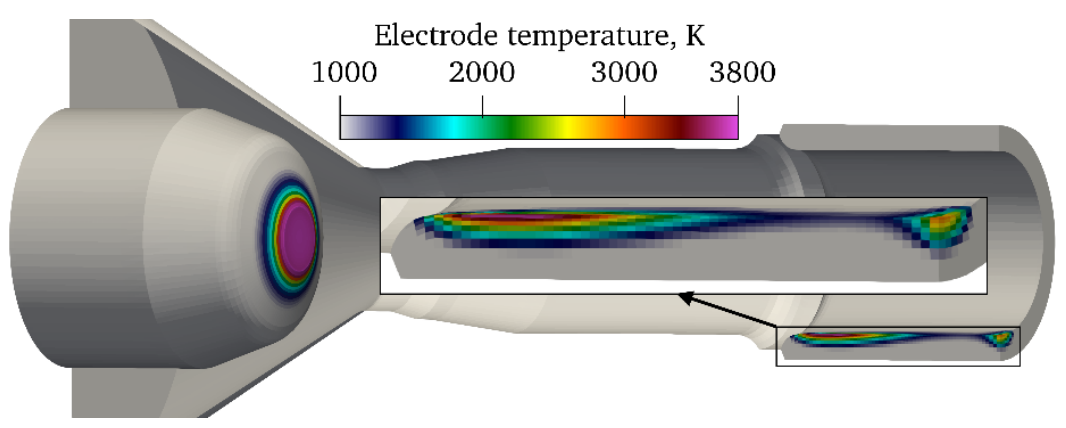

Fig. 9 Temperature of the electrodes with the anode inner surface zoomed in. Nozzle $\varnothing=9$ mm, 500 A, 60 NLPM Ar. Straight gas injection, no external magnetic field. 

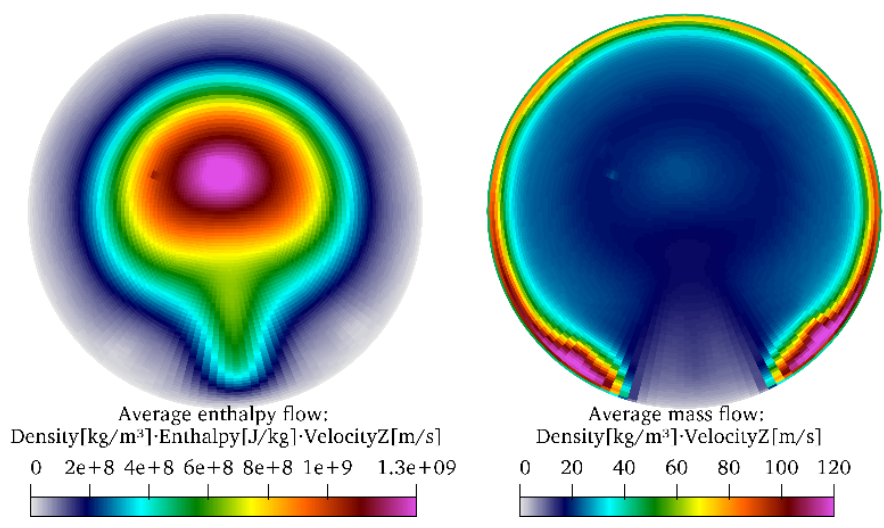

Fig. 10 Enthalpy flow rate and mass flow rate at the nozzle exit. Nozzle $\emptyset=9 \mathrm{~mm}, 500$ A, 60 NLPM Ar. Straight gas injection, no external magnetic field.

The predicted total enthalpy flow rate: $23.7 \mathrm{~kJ} / \mathrm{s}$ and total mass flow rate: $1.77 .10^{-3} \mathrm{~kg} / \mathrm{s}$ in the anode exit plane. The predicted gas specific enthalpy is $13.39 \mathrm{MJ} / \mathrm{kg}$ while the experimental one is $13.46 \mathrm{MJ} / \mathrm{kg}$.

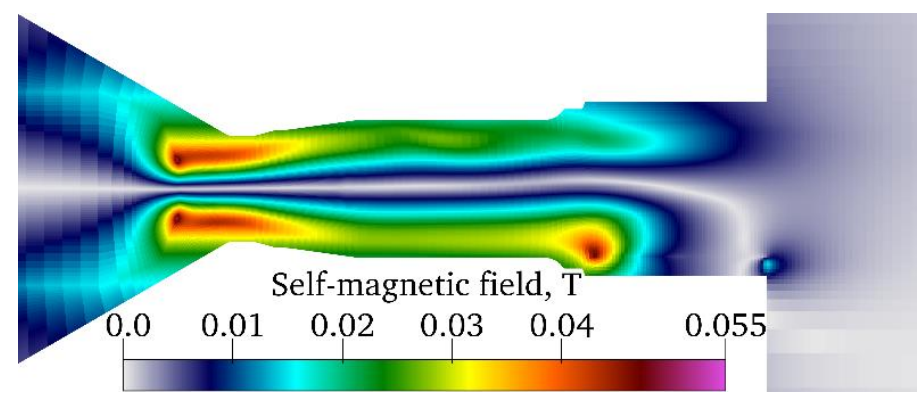

Fig. 11 Self-magnetic field generated by the arc current

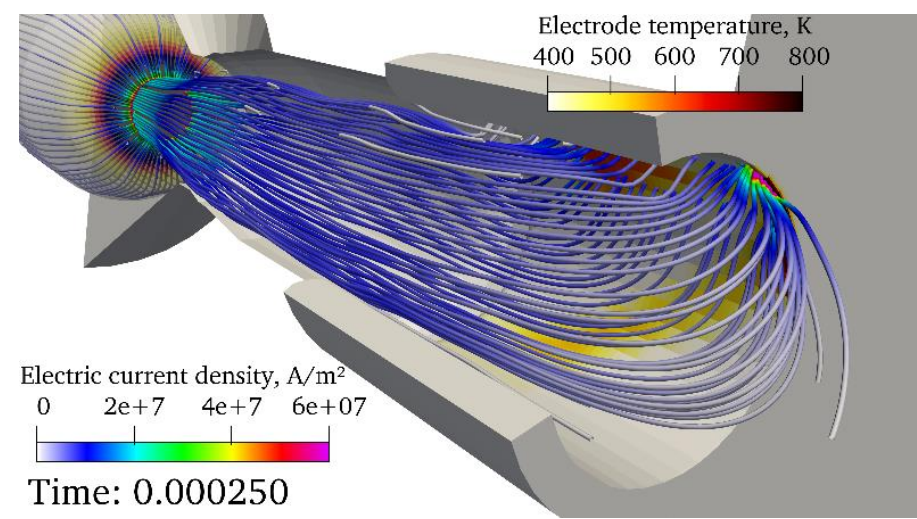



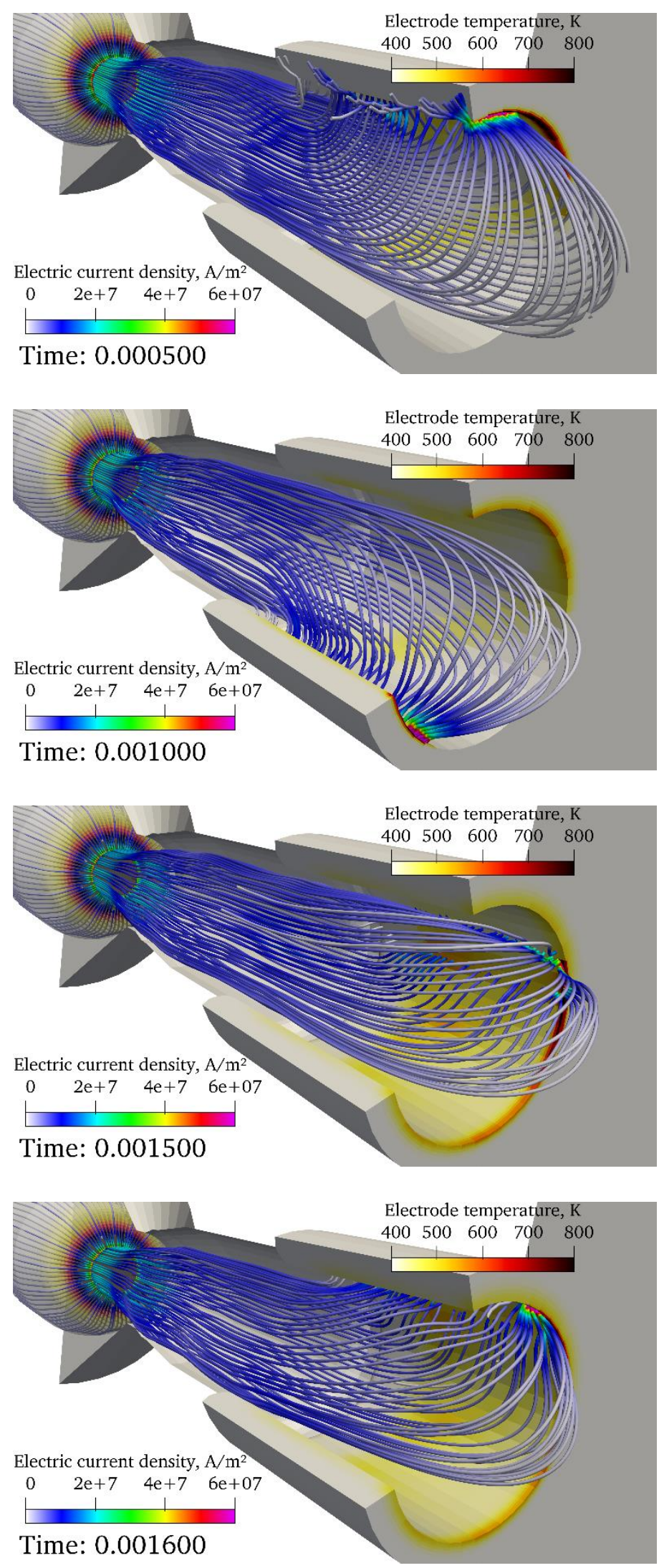

Fig. 12 Anodic arc root movement under the action of an external axial magnetic field of 0.05

T. Frequency of arc displacement: $800 \mathrm{~Hz}$ 


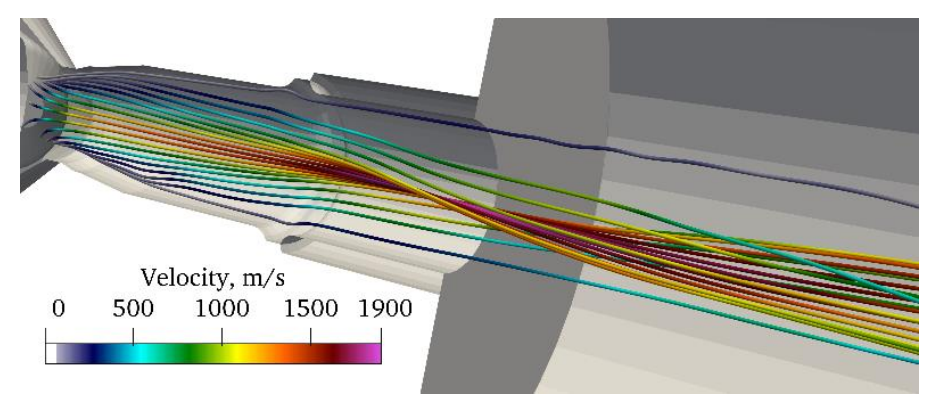

Fig. 13 Velocity streamlines for an external magnetic field of $0.05 \mathrm{~T}$

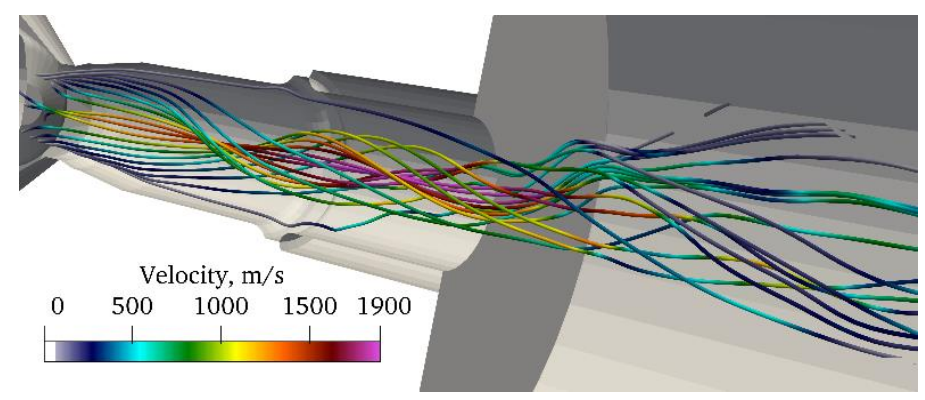

Fig. 14 Velocity streamlines for an external magnetic field of $0.2 \mathrm{~T}$

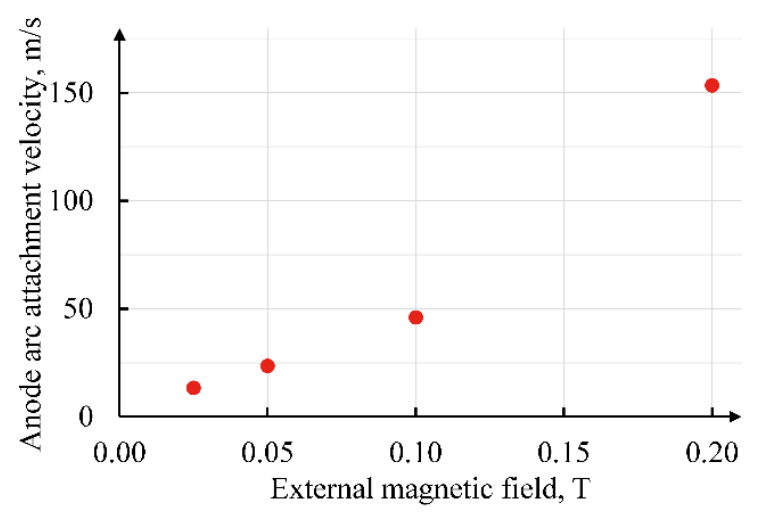

Fig. 15 Variation of the anode arc attachment velocity with the external magnetic field

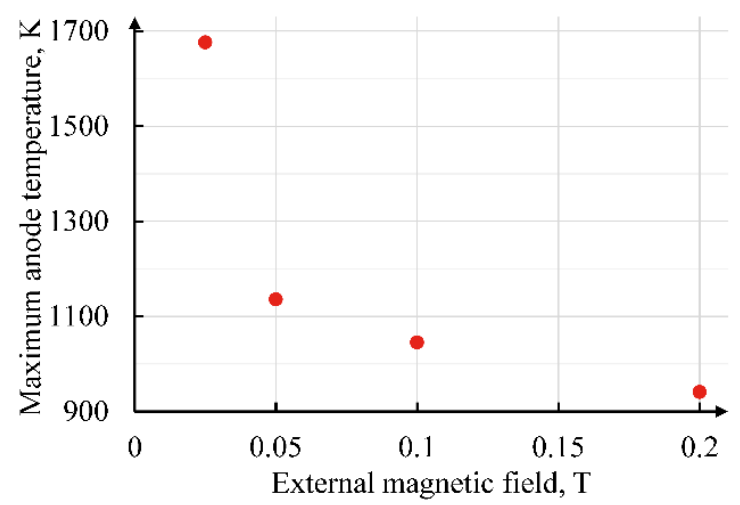

Fig. 16 Variation of maximum anode temperature with the external magnetic field 

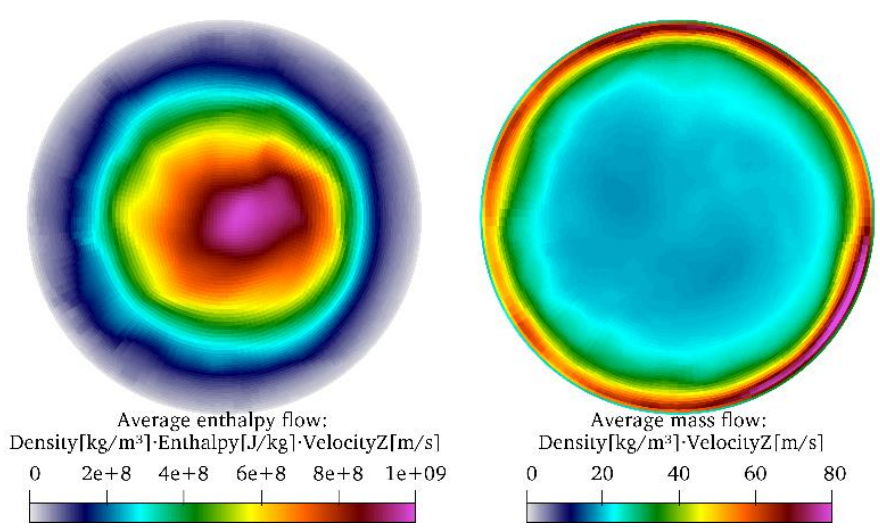

Fig. 17 Enthalpy flow rate and mass flow rate for an external magnetic field of $0.05 \mathrm{~T}$.

Predicted total enthalpy flow rate: $23.7 \mathrm{~kJ} / \mathrm{s}$ and total mass flow rate: $1.77 .10^{-3} \mathrm{~kg} / \mathrm{s}$ in the anode exit plane 
Table 1: Plasma torch operating conditions

\begin{tabular}{|l|l|}
\hline Nozzle diameter & $9 \mathrm{~mm}$ \\
\hline Arc current & $500 \mathrm{~A}$ \\
\hline Plasma gas & Argon \\
\hline Gas flow rate & $60 \mathrm{NLPM}^{*}$ \\
\hline Specific enthalpy & $13.46 \mathrm{MJ} / \mathrm{kg}$ \\
\hline
\end{tabular}

*NLPM: normal liter per minute

Table 2: Fluid and electromagnetic equations. $\overrightarrow{\mathrm{u}}$ and $\mathrm{h}$ are the fluid velocity and enthalpy; $\overrightarrow{\mathbf{J}}, \vec{B}$ and $\vec{E}$ are the electric current density, magnetic field and electric field, respectively; $\varphi$ and $\vec{A}$ are the electric and magnetic potential, $\rho, \lambda, C_{p}$ are the fluid density, thermal conductivity and specific heat, respectively and $\mu_{0}$ is the permeability constant $\left(4 \pi \times 10^{-7} \mathrm{H} \cdot \mathrm{m}^{-1}\right)$. $\overline{\overline{\mathbf{\tau}}}$ is the shear stress tensor, $\overrightarrow{\mathrm{J}} \wedge \overrightarrow{\mathrm{B}}$ the electromagnetic Lorentz force, $Q_{J}$ the Joule heating and $Q_{r}$ the radiation loss.

\begin{tabular}{|l|l|l|l|}
\hline \multicolumn{1}{|c|}{ Variable } & \multicolumn{1}{|c|}{$\boldsymbol{| c |} \boldsymbol{f}_{\boldsymbol{\psi}}$} & \multicolumn{1}{c|}{$\mathbf{S}_{\boldsymbol{\psi}}$} \\
\hline Mass & $\rho$ & $\rho \overrightarrow{\mathrm{u}}$ & 0 \\
\hline Momentum & $\rho \vec{u}$ & $\rho \vec{u} \otimes \vec{u}-\overline{\bar{\tau}}+p \overline{\overline{1}}$ & $\vec{J} \wedge \vec{B}$ \\
\hline Energy & $\rho h$ & $\rho \vec{u} h-\frac{\lambda}{C_{p}} \vec{\nabla} h$ & $Q_{J}-Q_{r}$ \\
\hline $\begin{array}{l}\text { Electric } \\
\text { Potential }\end{array}$ & 0 & $\sigma \vec{\nabla}(\varphi)$ & 0 \\
\hline $\begin{array}{l}\text { Magnetic vector } \\
\text { potential }\end{array}$ & 0 & $\vec{\nabla}\left(A_{i}\right)$ & $-\mu_{0} J_{i}$ \\
\hline
\end{tabular}

Table 3: Boundary conditions. The number in the first column correspond to the boundaries of the domain shown in Fig. 4.

\begin{tabular}{|l|c|c|c|}
\hline \multicolumn{1}{|c|}{ Variable: } & $\overrightarrow{\boldsymbol{u}}$ & $\boldsymbol{T}$ & $\boldsymbol{\varphi}$ \\
\hline 1: Inlet & $\vec{u}=\vec{u}_{\text {inlet }}$ & $T=300 K$ & $\partial_{n} \varphi=0$ \\
\hline 2: Cathode & $\vec{u}=0$ & $T=300 K$ & $\varphi=-\Phi(t)^{*}$ \\
\hline 3: Fluid boundary & $\vec{u}=0$ & $T=300 K$ & $\partial_{n} \varphi=0$ \\
\hline 4: Anode & $\vec{u}=0$ & $T=400 K$ & $\varphi=0$ \\
\hline 5: Outside plain surface & $\vec{u}=0$ & $T=300 K$ & $\partial_{n} \varphi=0$ \\
\hline $\begin{array}{l}\text { 6: Outside cylindrical } \\
\text { surface }\end{array}$ & $\vec{u}=0$ & $T=300 K$ & $\partial_{n} \varphi=0$ \\
\hline 7: Outlet & $\partial_{n} u_{i}=0$ & $\partial_{n} T=0$ & $\partial_{n} \varphi=0$ \\
\hline
\end{tabular}

*Imposed arc voltage is recomputed with respect to total Joule power and prescribed electric current. 
Table 4: Variation of the swirl number $S_{w}$ from gas inlet to torch nozzle exit for different gas injection angles ( $\mathrm{Sw}$ is defined as the ratio of the axial flux of the tangential momentum to the axial flux of the axial momentum normalized by the anode radius).

\begin{tabular}{|c|c|c|c|}
\hline & \multicolumn{3}{|c|}{ Swirl Number } \\
\hline $\begin{array}{c}\text { Gas Injection } \\
\text { angle }\end{array}$ & Inlet & $\begin{array}{c}\text { Middle of the } \\
\text { channel }\end{array}$ & Nozzle exit \\
\hline $0^{\circ}$ & 0 & 0 & 0 \\
\hline $10^{\circ}$ & 0.43 & 0.011 & 0.005 \\
\hline $25^{\circ}$ & 1.2 & 0.029 & 0.015 \\
\hline $45^{\circ}$ & 2.8 & 0.059 & 0.031 \\
\hline
\end{tabular}

Table 5: Variation of the swirl number $\mathrm{Sw}$ at the middle of the torch and at nozzle exit for different values of external magnetic field.

\begin{tabular}{|c|c|c|}
\hline Bext & $\begin{array}{c}\text { Middle of the } \\
\text { channel }\end{array}$ & Nozzle exit \\
\hline 0.025 & 0.007 & 0.012 \\
\hline 0.05 & 0.015 & 0.040 \\
\hline 0.1 & 0.027 & 0.082 \\
\hline 0.2 & 0.050 & 0.15 \\
\hline
\end{tabular}

